\title{
Crise e rodadas de neoliberalização: impactos nos espaços metropolitanos e no mundo do trabalho no Brasil
}

\author{
Crisis and neoliberalization rounds: impacts \\ on metropolitan areas and on the labor world in Brazil
}

Carlos Antônio Brandão*

\begin{abstract}
Resumo
0 objetivo deste ensaio é analisar a crise e as recentes rodadas de neoliberalização nas escalas mundial e nacional, procurando discutir os possíveis impactos no mundo do trabalho, sobretudo nos espaços urbano-metropolitanos no Brasil. Partindo da natureza do processo de urbanização brasileiro, busca apontar a lógica daquelas rodadas e das transformações geopolíticas e geoeconômicas atuais, procurando situar o Brasil nesse contexto. Analisa a rede urbana e o fenômeno da metrópole, enquanto sistema urbano socioeconômico e socioespacial complexo, como um lócus importante para se investigar as mudanças no mundo do trabalho no Brasil. Conclui afirmando que nos últimos 20 anos, de 1995 a 2015, o Brasil sofreu três rodadas de neoliberalização, que lançaram mão de dispositivos, mecanismos e instrumentos bastante diferenciados de experimentações re-regulatórias, com variadas repercussões, que requerem mais aprofundados estudos comparativos.
\end{abstract}

Palavras-chave: trabalho; metrópole; Brasil; neoliberalização; crise.

\begin{abstract}
The purpose of this essay is to analyze the crisis and recent neoliberalization rounds on the global and national scales, aiming to discuss possible impacts on the labor market, especially in urban-metropolitan areas in Brazil. Based on the nature of the Brazilian urbanization process, it seeks to identify the logic of those rounds and of current geopolitical and geo-economic transformations, trying to place Brazil within this context. It analyzes the urban network and the phenomenon of the metropolis, which is an urban and complex socio-economic and socio-spatial system, as an important locus to investigate changes in the labor world of Brazil. It concludes by arguing that, in the last 20 years, from 1995 to 2015, Brazil underwent three neoliberalization rounds that used very different devices, mechanisms and instruments of re-regulatory experiments. They have had different repercussions and require in-depth comparative studies.
\end{abstract}

Keywords: labor; metropolis; Brazil; neoliberalization; crisis. 


\section{Introdução}

Sem pretender discutir as complexas articulações teóricas entre trabalho e produção social do espaço, caberia iniciar este artigo apenas lembrando que, no final dos anos 1960 e início dos 1970, estruturou-se um campo de conhecimento que poderia ser denominado urbanismo e economia política da urbanização que, procurando criticar a hegemonia teórica da Escola de Chicago (Park, 1991), apontou importantes questões sobre a reprodução da força de trabaIho e do espaço urbano. Alguns autores deram grande contribuição a esse debate.

Castells partiu do pressuposto de que o espaço urbano é estruturado, sendo, assim, fundamental conceber a cidade como projeção da sociedade no espaço e tomar o urbano como o espaço da reprodução simples e ampliada da força de trabalho, buscando teorizar sobre os meios de consumo coletivo e as lutas sociais por sua provisão, em que "consumo coletivo refere-se, no essencial, ao processo de reprodução da força de trabalho e ao processo de reprodução das relações sociais" (Castells, 1983, p. 492).

Lojkine (1997, p. 124) observou que a urbanização é um "modo de aglomeração específica do conjunto dos meios de reprodução (do capital e do trabalho) que se vai tornar, por si mesmo, condição sempre mais determinante do desenvolvimento econômico".

Harvey (1980) construiu uma argumentação centrada no fato de que o por ele chamado de urbanismo vai requerer a circulação de excedente, do trabalho disponível intercambiado como a mercadoria força de trabalho, em um mercado supostamente "livre", mas também a aglomeração e a concentração desse excedente e desse trabalho-mercadoria no espaço urbano. Nesse contexto,

a cidade funcionará como um lugar de disposição de produto excedente ${ }^{1}$ [...]. A criação das necessidades na sociedade urbana contemporânea são todas manifestações diferentes desse mesmo fenômeno. A cidade pode assim ser interpretada parcialmente com um campo destinado a gerar demanda efetiva. (Harvey, 1980, p. 195)

Interessante notar que Harvey partiu nessa obra das reflexões de Polanyi (1980), que tratou de discutir o trabalho como uma das três "mercadorias fictícias" (ao lado da terra e do dinheiro). Segundo ele, em toda a história da humanidade, todas as anteriores formas de estruturações sociais da produção tiveram o trabalho inserido na organização geral da sociedade, mas o momento histórico da expansão do mercado autorregulável exigiu a separação institucional da sociedade em duas esferas apartadas, a econômica e a política. 0 mercado atacou as salvaguardas que protegiam o trabaIho da livre comercialização, estabelecendo o seu intercâmbio generalizado como uma mercadoria qualquer, subordinando, dessa forma, a substância da própria sociedade, que é o trabaIho, às suas próprias leis mercantis.

Por seu lado, Jacobs (1969), após defender a importância e mesmo a precedência das cidades sob o campo, discutiu como o novo trabalho surge. De acordo com essa obra, a economia das cidades se expande e se desenvolve pela forma como adiciona novos tipos de trabalho aos já existentes. A autora apresentou vários exemplos para sustentar sua tese de que um tipo de trabalho conduz a outro, em 
um processo evolutivo no qual novos produtos e serviços são adicionados e novas coincidências de habilidades são combinadas. Novos trabalhos, que clamam por novas tarefas e renovados labores, criam novas somas e massas e interfertilidade de atos e atividades, que são adicionados a alguns trabalhos anteriores (não ao conjunto deles, mas a algum fragmento de trabalho muito específico), e é nesse processo que se engendram e multiplicam novas divisões sociais do trabalho que podem aprofundar o convite a uma variedade de outros trabalhos a serem disponibilizados e apropriados no espaço urbano.

Desse modo, de uma forma ou de outra e sob distintas perspectivas, esses autores clássicos tinham colocado o trabalho no centro da análise do processo capitalista de produção e de urbanização. Entretanto, essa foi uma tradição que foi se perdendo, até quase se dissipar no debate pós-1990, por motivos que não caberia aqui discutir, mas que têm relação com a polêmica sobre o fim da centralidade do trabaIho (Gorz, 1999 e Castel, 1998 e 2010).

Independentemente dos caminhos que tomou tal polêmica, o certo é que o trabalho continua a ser uma categoria central e fundante dos laços de sociabilidade, um dos alicerces de integração, prestígio e coesão sociais, e elemento crucial da organização da vida social e de uma sociedade urbana, que tem nas relações de trabalho alguns de seus principais nexos sociais.

Há pouco mais de uma década, na maioria dos países da América Latina, um conjunto de políticas de cunho social vinha construindo algum patamar de maior homogeneização social, com uma melhor estruturação dos seus respectivos mercados de trabalhos urbanos, com aumento de segurança, proteção e formalização de suas relações trabalhistas.

No caso específico do Brasil, no período entre 2003 e 2015, avançou-se muito em um conjunto de políticas sociais voltadas à proteção das camadas mais destituídas da população e na expansão do mercado interno de consumo popular. Caberia destacar o avanço das políticas de transferência de renda, 0 crescimento formal do emprego, a valorização do salário mínimo, a expansão do volume e das linhas de crédito (inclusive o consignado), a expansão da capacitação e do ensino superior, etc., além de progressos localizados na luta mais geral das últimas décadas, travada pela permanência das conquistas e dos ganhos sociopolíticos da Constituição Cidadã de 1988, com melhorias na distribuição de renda e na qualidade do mercado de trabalho.

Não obstante diversos fatores que apontaremos neste artigo, concorreram para que, atualmente, através de uma nova rodada de neoliberalização, todos aqueles compromissos, processos, mecanismos e estruturas que vinham sendo construídos ou fortalecidos para a reorganização de uma sociedade salarial urbana mais complexa estejam agora sob frontal e potente ataque na conjuntura mundial e nacional.

0 aprofundamento da crise mundial, as notáveis movimentações geopolíticas e geoeconômicas em processo e as opções conservadoras pelas decisões prefiguradas pelas forças do mercado têm conduzido à reestruturação regressiva dos mercados de trabalho e à individualização, precarização e intensificação da exploração da força de trabalho, colocando em xeque o movimento de mobilidade ascendente na base da pirâmide social e a 
formalização das ocupações que estavam se estruturando, desmontando, assim, sistemas de proteção, garantias e segurança que vinham sendo duramente erguidos, mesmo sob forte ataque antipopular nas últimas décadas.

Nesse contexto, este artigo pretende analisar o período recente de crise e rodadas de neoliberalização nas escalas mundial e nacional, procurando discutir os possíveis impactos nos espaços urbano-metropolitanos e no mundo do trabalho, com destaque para o caso brasileiro.

\section{Transformações recentes no capitalismo (Norte e Sul) e no mundo do trabalho}

Podemos constatar que, nesta segunda metade da segunda década do século XXI, transformações profundas e pervasivas nas "mercadorias fictícias", terra, dinheiro e trabalho (Polanyi, 1980), estão em curso no sistema capitalista, em suas mais variadas escalas espaciais recorrentemente reproduzidas. Há, em processo, um extraordinário reordenamento hierárquico e hegemônico escalar-espacial no plano mundial de reprodução dos capitais e da força de trabalho. Há, ao mesmo tempo, excepcionais metamorfoses na escala nacional que tomam a forma de rodadas de re-regulação daquelas três mercadorias e de reorganização e reconstrução de novas coerências estruturadas de caráter econômico, político e social. Estão em curso mudanças intensas nos marcos da reprodução social-classial, que tomam a forma de ciclos acelerados de experimentações regulatórias impulsionados pela crise, com repercussões de natureza estrutural, desigualmente distribuídas, no sistema capitalista, em suas relações interescalares, com distintas "variações" temporais e espaciais "das" e "nas" diversas periferias do sistema.

0 certo é que oito anos já se passaram desde que a crise de 2008 estourou no centro do capitalismo e se espalhou diferenciadamente por todo o globo, e continuamos desafiados a buscar entender e separar analiticamente 0 que é novo e o que é velho: no modo de funcionamento do sistema capitalista; nas transformações no mundo da produção e dos negócios e no mundo do trabalho e nos modos de sociabilidade; nos seus desdobramentos socioespaciais, etc.

Não há dúvida de que estamos imersos em momento de radical condensação histórica e de verdadeiras erupções geopolíticas e geoeconômicas na escala mundial: o acirramento das rivalidades nas escalas mundial, nacional e regional, com a exacerbação do embate competitivo entre os sistemas interestatais e entre os sistemas interempresariais (Fiori, 2014); a consolidação do regime de acumulação sob dominância da valorização financeira, orientado de forma míope pelo capital portador de juros (Chesnais, 2005); a hegemonia sino-americana e o papel da China enquanto duplo polo da economia internacional (Medeiros, 2006); a lógica das deslocalizações produtivas dos gigantescos conglomerados industriais, em busca de recursos naturais e de mão de obra disponíveis, abundantes e baratas. Estas e outras facetas, dentre as vigorosas transformações em processo no capitalismo do século XXI, abalam as estruturas materiais e societárias, em um ambiente de baixo ou nenhum crescimento econômico, regressão civilizatória, intolerâncias e 
brutalidades despolitizadas, nas mais diversas escalas espaciais.

No plano escalar mundial, caberia destaque à dinâmica das duas hierarquias mais decisivas: a da força da(s) moeda(s) conversível(eis) de curso internacional (a geoeconomia do "poder de pagar", aquela das decisões envolvendo as articulações coercitivas das moedas - das relações entre espaço e riqueza); e a da força militar (a geopolítica do "poder de matar", aquela das decisões hegemônicas e/ou imperiais - das relações entre espaço e poder). As disputas por hegemonia nos sistemas interestatais e interterritoriais e as hierarquias dos estados, moedas e armas, que esculpem a nova/velha forma do mundo, revelando explicitamente que esse capitalismo é dirigido pelos grandes interesses do poder financeiro, pela força de estruturas empresariais agigantadas e pelas capacidades renovadas de comando sobre as mais diversas formas de exploração da força de trabalho e da natureza.

A quadra histórica é de indeterminação, do predomínio da exceção, do emergencial permanente, da violência extraeconômica antidemocrática e da contrarreação conservadora. Os espaços públicos são deslegitimados, e o Estado fica refém das forças privadas concentradas, tanto das mais "modernas", quando das mais retrógradas, sem capacidade de ação estratégica que possa ser sancionada pela maioria da população. É momento do que Gramsci (2007) caracterizou de hegemonia da pequena política, das questões parciais e rasteiras.

A literatura crítica que investigou esse momento pós-1990 na escala do capitalismo mundial se lançou ao escrutínio rigoroso da natureza do fenômeno da globalização. Foi uma trajetória muito instigante que arrancou da crítica a visão prevalecente, de viés jornalístico e conservador, que realizava descrições monolíticas tomando a globalização como uma onda abarcativa, unidirecional, implacável, não contestável e inexorável, que teria o poder de aniquilar os estados nacionais e estabelecer, sem mediações, diálogos sinérgicos entre o local e o global (Ohmae, 1996). 0 que é no mínimo estranho, como afirma Desai (2013), é que a globalização e o cosmopolitismo têm poucos defensores explícitos, mas muitos políticos e intelectuais "realistas" que defendem que ela é "imparável", isto é, impossível de ser contida, e a ela todos os entes, desde nações a indivíduos, devem se submeter de forma homogênea e subalternizada.

Em seguida, a literatura crítica partiu para o relato aprofundado das experiências concretas de neoliberalismo (Thatcher, Reagan e Pinochet), para avançar ao entendimento conceitual da neoliberalização como um processo contraditório que se desenrola nos últimos 35 anos, sempre de modo diversificado, espacialmente desigual e dependente da trajetória e que tem se estendido e arraigado nas mais variadas escalas. Peck (2010a), um dos principais expoentes dessa nova literatura, propõe uma definição processual de neoliberalização que rompa com a visão estática e de coordenadas fixas - para colocar ênfase na adaptabilidade e nos processos contestáveis e contraditórios -, e de acomodação programática, que fazem e refazem, concreta e e de modo situado, as experimentações de políticas orientadas pelo e para o mercado. 0 objetivo central desse esforço teórico e analítico é, entre outros, discutir seus efeitos diferidos em contextos variegados, a fim de 
explorar cenários possíveis de construção de formas de contraneoliberalização na atual reestruturação regulatória do capitalismo (Brenner, Peck e Theodore, 2012).

Esses autores propuseram uma periodização muito interessante, distinguindo dois momentos nos processos de neoliberalização. Nesse sentido, as formas neoliberalizadoras ocorreriam em duas rodadas (fases/faces) de reestruturação regulatória bastante distintas. Em uma primeira, que denominam Roll-Back, ou seja, de ataque ofensivo, em que se promove o desmantelamento de instituições, desorganizando centros de poder, espaços burocráticos, etc. e procurando, por diversos dispositivos, disciplinar sujeitos coletivos. Em uma segunda rodada, chamada de Roll-Out, de re-regulação, há um reentrincheiramento, enfrentando modos de governança diversos erigidos anteriormente e realizando uma incursão e implantação regulatória que garanta modos de conformação aos desígnios dos mercados (Peck, 2010a, p. 22).

Esse debate é central para se aprofundar nas investigações de como os processos neoliberalizantes se estendem e se arraigam, em rodadas cíclicas e contingentes, seja em um primeiro momento mais destrutivo de desmonte, seja em um momento mais proativo de re-regulamentação, remontagem e proteção/ reentrincheiramento.

Outro elemento importante na periodização foi distinguir conjunturas históricas bastante distintas nos capitalismos atlânticos, norte e sul, do pós-guerra: com a passagem de um Estado Nacional de Bem-Estar Keynesiano (KNWS), a um posterior, de Regime Shumpeteriano de Workfare Pós-Nacional (SPWR) (Jessop, 2006 e Brenner, 2004).
No interior dessa distinção de períodos, um aspecto fundamental ressaltado, no âmbito do mundo do trabalho, foi a passagem do que os autores chamaram de um regime regulatório baseado no Welfare para um residual de Workfare, marcado pela reconversão da força de trabalho. Com esta última expressão, queriam chamar a atenção para o fato de que o ingresso e a permanência, com segurança, no mercado formal de trabalho se tornam um pré-requisito para se ter acesso a saúde e a outros benefícios sociais (Peck e Teodore, 2010; Peck, 2010b), não sendo mais vistos como direitos do cidadão, mas apenas do consumidor empregado.

Se, nos anos 1980, o propósito do campo de ação do processo de neoliberalização era o desmantelamento agressivo do Estado (Roll-Back), a partir dos anos 1990 a ênfase passou a ser colocada no Roll-Out, fundado na institucionalização política mais concertada do neoliberalismo. As pesquisas sobre as mudanças morfológicas do Estado no capitalismo atual, em suas etapas de expansão/contração de seus papéis são fundamentais para se pensar a formulação de políticas orientadas pelo/para o mercado (Fernández, 2016a e 2016b).

Nos países periféricos, tais processos se dão com alguma defasagem temporal, como veremos. Nesse sentido, torna-se urgente investigar concretamente, em variegados contextos georregulatórios, novas formas de desenvolvimento desigual e o que Harvey (2016) denomina novas lógicas de formação, propagação e gestão de crises.

No contexto georregulatório do que poderia ser denominado Capitalismo Sul Atlântico Periférico Subdesenvolvido Latino-Americano, é preciso partir do rico patrimônio 
científico-acadêmico-político, que durante meio século desenvolveu um pensamento crítico, bastante original, que acumulou uma interpretação cíclico-dinâmica da reestruturação espaço-temporal da contradição histórico-sistêmica das relações centro-periferia (Fernández, 2016a e 2016b), procurando, com bastante originalidade, a partir da América Latina, discutir a problemática da não plena constituição da escala nacional.

Segundo essa interpretação, o caráter restrito, parcial e de incompletude das forças produtivas nacionais, com uma oferta ilimitada de mão de obra destituída de direitos, que formava uma massa marginalizada nos espaços urbano precarizados, dentre outras características da condição periférica-dependente, e tornava esses espaços nacionais quase meros prolongamentos e apêndices do espaço econômico dos países desenvolvidos.

Os seguidores dos pioneiros latino-americanos contribuíram com análises aprofundadas da investigação da natureza do capitalismo periférico, questionando os porquês de não se lograr estabelecer nesses países: 1) um núcleo endógeno de acumulação industrializante; 2) um padrão autônomo e sustentado de financiamento e de crédito de longo prazo; 3) um sistema de aprendizado capaz de endogeneizar o progresso técnico; 4) um sistema de exação que pudesse constituir um sistema tributário nãoregressivo e penalizador do rentismo e do patrimonialismo capaz de suportar com fundos públicos um Estado com capacidade estratégica; e 5) um mercado de trabalho moderno e estruturado com qualidade, capaz de incorporar os ganhos de produtividade em cada momento histórico.
Apontavam que na América Latina persistiam disritmias, assincronias e incompatibilidade entre pelo menos cinco estruturas: as de consumo, distribuição de renda, propriedade, estrutura produtiva e estruturas ocupacionais, que eram ainda agravadas pela decisiva presença das grandes corporações multinacionais nos principais elos das cadeias produtivas de maior densidade tecnológica, configurando uma estrutura produtiva bastante heterogênea e de baixa qualidade na geração de emprego.

Precisamos retomar esse debate clássico do pensamento crítico latino-americano, buscando reatualizá-lo para um mundo cada vez mais asiático e em que quase todos os impérios seculares ou milenários voltaram à cena do tabuleiro geopolítico.

Se não cabe aqui realizar essa tarefa, é fundamental lembrar que na atualidade, nos principais países da América Latina, os temas da desindustrialização, reprimarização, neoextrativismo, entrega do patrimônio comum e/ ou público à "iniciativa privada" forânea, a expansão dos enclaves de exploração de recursos naturais, a especialização regressiva em bens primários, dentre outros fenômenos, estão todos de volta e se reatualizam na velha narrativa da necessidade de modernização desses países, imposta pela presente rodada de neoliberalização, que varre todo o continente neste ano de 2016.

No Brasil, para além do avanço do poder do agronegócio, da extração mineral e de suas respectivas infraestruturas de logística, a energia e a questão do petróleo da camada do Pré-Sal são colocadas no centro dessa agenda neoconservadora. As discussões do grau de autonomia de decisão desse espaço nacional - que opta, 
por exemplo, por especialização regressiva, com concentração da estrutura produtiva, já bastante heterogênea, na oferta de commodities de baixa elaboração e na exploração de recursos naturais, utilizando-se de "estratégias" de ajuste passivas e defensivas, baseadas em competitividade espúria, não voltadas para a aprendizagem - são reveladoras da limitação ou ausência de projetos de desenvolvimento nacional de países como o Brasil.

Atravessamos profunda crise política e econômica na América Latina e no Brasil hoje, em ambiente de baixo crescimento e em contexto internacional de abrangente reorganizações sistêmicas, nacionalistas, interterritoriais e interempresarias. 0 caráter do regime de crescimento imposto ao continente, de extração e exploração dos recursos naturais minerais, agrícolas e energéticos (tanto os renováveis quanto os exauríveis, tais como as reservas de petróleo e os depósitos minerais não energéticos), repõe as problemáticas estruturais de nossa experiência histórica periférica, com congênita insuficiência de agentes dinâmicos e estruturantes dotados de liderança e vigor para buscar penetração e inserção internacional mais ativas e dinâmicas na mutante geopolítica e geoeconomia na escala mundial.

0 momento é de recessão e de profunda crise institucional e política, gerando muitas incertezas quanto ao futuro, mesmo o mais próximo. Em contexto de rearranjos complexos, as economias emergentes estão mergulhadas em profunda recessão, imposta pela:

contração da demanda puxada pela desaceleração da China, queda nos preços das principais commodities, elevada volatilidade dos mercados financeiros, desvalorização das moedas, fuga de capitais desde a sinalização de alta da taxa de juros básica nos Estados Unidos, contração do crédito [...]. Para o Brasil, o FMl estimou queda de 3,5\% em 2016; para a Rússia, a contração foi estimada 1\% em 2016. (Cintra, 2016, p. 55)

A exacerbação da coerção concorrencial intercapitalista e interestados territoriais tem promovido uma colossal aceleração da intensificação do trabalho, com redução dos salários reais, diminuição da combatividade, com redução da segurança, estabilidade, proteção, precarização e individualização, com o desmonte dos compromissos de classe típicos do momento anterior.

\section{Espaços urbanos complexos e subdesenvolvidos e a reprodução da força de trabalho}

Cinquenta anos de industrialização acelerada (1930/1980), intensos fluxos migratórios, urbanização complexa (simultaneamente, metropolizada, interiorizada e com centros regionais medianos, isto é, uma rede urbana paradoxalmente concentrada e dispersa ao mesmo tempo), potente mercantilização, integração e "nacionalização" dos mercados (de bens, de trabalho e de consumo), sofisticação das classes sociais, sobretudo da fração média, dentre outros fatores estruturais, conduziram à configuração de uma sociedade urbana complexa e no mínimo paradoxal e incompleta/travada, sem urbanidade, sem a estruturação de um verdadeira Sociedade Salarial e sem um Estado de Bem-Estar Social digno desse nome. 
Mesmo com a insurgência de lutas políticas e a forte participação estatal na estruturação de uma provisão massiva de bens, infraestruturas e serviços públicos (porém insuficientes e sem qualidade adequada), dentre outros fatores, não se logrou constituir o direito à cidade.

Nesse contexto as re-regulações antipopulares e antidemocráticas constantes ao longo da história das mercadorias fictícias, terra, dinheiro e trabalho, tornam-se cruciais para entender o Brasil. A mercadoria terra foi interditada para a maioria dos habitantes, o que conduziu às práticas da autoconstrução de moradia ilegal, que vem cumprindo um papel fundamental para o rebaixamento do custo da força de trabalho, segundo Oliveira (1979). Explicitou-se um processo de modernização conservadora no qual o que se apresenta como "moderno" se alimenta do atrasado, com a produção de um ambiente construído (moradia, transporte, saneamento) precarizado, erguido ao lado e em paralelo aos mercados formais e estruturados, configurando uma "urbanização de baixos salários" (Maricato, 2015), com alta segregação socioespacial ao longo do tecido urbano.

A mercadoria dinheiro sempre teve 0 seu valor regulado politicamente, no sentido de garantir, de modo diferenciado por classe, a adequada liquidez, promovendo a recomposição frequente dos portfólios dos afortunados e a segurança macroeconômica para as oportunidades de inversão de massas monetárias excedentárias, redundantes e ociosas entre as opções preferencialmente patrimonialistas e rentistas. Procurou-se garantir a extração, a circulação e a retenção dos excedentes mercantis e a liquidificação de suas aplicações financeiras-imobiliárias-fundiárias, sempre aprofundando a subsunção passiva aos movimentos dos capitais internacionais de moeda conversível, refúgio geral assegurado da riqueza abstrata da grande elite.

A mercadoria força de trabalho foi permanentemente aviltada, confrontada antagonicamente, vulnerabilizada em cada rodada de desregulação, perdeu salvaguardas, foi pressionada, sempre culpabilizada por impedir maiores taxas de crescimento e aumentos na produtividade, nos mais diversos ciclos históricos conjunturais. Recorrentemente, a narrativa construída pelos poderes constituídos é que 0 mercado de trabalho está enrijecido e precisa ser flexibilizado, requerendo, assim, re-regulação no sentido de retirar as fricções ao pleno funcionamento do mercado livre de trabalho, tornar mais maleáveis as normas rigorosas, enfrentar os "corporativismos" (direitos adquiridos), garantir um tratamento individualizado da mercadoria força de trabalho pela "iniciativa privada". 0 resultado é a precarização dos nexos de sociabilidade dos "de baixo" e o reestabelecimento do poder da classe empresarial dos "de cima".

Ao longo de sua história, o Brasil apresentou uma trajetória sui-generis no Ocidente, ao avançar suas bases materiais e constituir processos potentes, acelerados e simultâneos, com as características de: modernização conservadora; industrialização truncada e incompleta (sem núcleo inovador e sem regime de financiamento de longo prazo); e urbanização expansiva, precarizada e espoliativa (Kowarick, 1979), carente de urbanidade e com travamento e interdição do acesso aos direitos para a maioria de sua população (uma parte da qual detendo características de massa inorgânica, no sentido de Caio Prado Jr., nunca absorvida 
adequadamente pelos mercados formais do núcleo moderno capitalista). Forças sociais heterogêneas esculpiram no território nacional uma das dez maiores e mais complexas economias e sociedades nacionais-urbanas-industriais e uma das sociedades mais desiguais, excludentes e predatórias do planeta. Uma nação com construção travada, tendo, no núcleo de seu poder, uma das elites mais conservadoras e retrógradas já existentes na história mundial e uma imensa massa populacional destituída de direitos, cidadania plena e acesso adequado a bens e serviços coletivos.

O Brasil montou, ao longo de décadas, uma economia urbana moderna e diferenciada, com complexa estrutura produtiva (industrial, agropecuária e terciária) e heterogeneidades sociais, regionais, rurais e culturais marcantes. Ergueu, com enorme rapidez e conservadorismo, uma das sociedades urbanas de massa mais complexas do planeta. Uma sociedade multicultural vivendo em uma economia urbana simultaneamente moderna, de "fuga para a frente" (territorial e dos direitos), excludente, de predação ambiental e social, ocupando espaços com irregularidade e exclusão.

Os próximos anos serão de uma urbanização difusa e complexa, de baixo crescimento econômico e sob sérios riscos de regressão social e política.

0 Brasil pode ser caracterizado, ao longo de sua história, como uma máquina potente de produção de cidades e simultaneamente por processo de rápida urbanização precarizada e marcada por várias expressões de destituição para a maioria de sua população. Uma urbanização complexa (simultaneamente, metropolizada, litoralizada e interiorizada), com variados centros regionais medianos e uma miríade de cidades locais-pequenas-quase-rurais.

Esse processo múltiplo e diversificado requer que se lance mão da rede urbana enquanto uma mediação teórica e analítica imprescindível entre escalas espaciais, rede urbana e porte de cidade, a partir da análise de seus núcleos organizadores de processos socioeconômicos variados e centros de poder e de emanação de decisões fundamentais.

A rede urbana expressa e potencia uma hierarquia de decisões que são tomadas e que "circulam" e se encadeiam no território. Ela "é um reflexo, na realidade, dos efeitos acumulados da prática de diferentes agentes sociais" (Corrêa, 2007, p. 27). Os principais centros urbanos da rede precisam ser investigados em sua dinâmica de emanação e coordenação de decisões cruciais das economias micro e mesorregionais ou nacionais e pontos de importantes interconexões com a economia supralocal.

As pequenas cidades, ou cidades-locais, na denominação de Milton Santos, que se apresentam como elemento de ligação entre o meio urbano e as variadas ruralidades brasileiras, acabam tendo um papel importante a partir de daquele especificado pelo conjunto do sistema de cidades.

As cidades médias, ao deterem centralidade e estarem localizadas em pontos estratégicos de determinado sistema de cidades, cumprem um papel decisivo nesse contexto. Enquanto espaço de transição (Sposito, 2007), elo urbano-regional de retransmissão e nó de comando e de interação com suas hinterlândias e interfaces entre cidade e região. A cidade média, por apresentar "interações espaciais intensas, complexas, multidimensionais e marcadas pela multiescalaridade" (Corrêa, 
2007, p. 30), poderia se constituir em privilegiada plataforma territorial de força de trabaIho combinada em escala particular, desempenhando um papel de lugar central com destacada posição relativa na hierarquia regional, de circulação, com amplo alcance territorial.

As metrópoles - enquanto sistemas urbanos econômicos e sociais complexos - derivam de determinações e processos plurais, que resultam de seus caracteres distintivos de alta densidade demográfica, porte e adensamento de funções urbanas, integração de infraestruturas física e econômica, etc., seu padrão específico de ocupação e uso do solo, seus deslocamentos e assentamentos humanos peculiares e sua alta densidade de interações e articulações intra e intersetoriais que se constroem em determinado tecido metropolitano territorializado.

Trataremos privilegiadamente aqui dos espaços metropolitanos, por se constituírem em territórios mais complexos e com centralidade e nodalidade decisiva na rede urbana.

0 atual estágio de urbanização planetária (Brenner, 2014) gerou um processo total, extensivo, difuso, disperso e onipresente de espraiamento do fato urbano, colocando o espaço metropolitano como lócus privilegiado dessas transformações

Aquelas transformações sistêmicas em curso na escala mundial, apontadas na seção anterior, têm como seu lócus privilegiado os nós principais representados pelos espaços metropolitanos.

0 que caracteriza o fato metropolitano é justamente esse conjunto orgânico e sistêmico de moderno sistema viário regional, suporte de infraestrutura em rede, alta mobilidade intrametropolitana espacial de sua população (com alguns deslocamentos regulares - diários - específicos das classes sociais no espaço). Mas, também, a retenção, a combinação e a disponibilização adequadas de massas trabalhadoras disciplinadas, na quantidade e qualidade requeridas pela acumulação de capital urbana, em uma base de provisão que pode ser mobilizada e acionada diária, situada e cotidianamente (Siqueira, 2010).

Enquanto fato urbano superior, o meio metropolitano é também de organização da classe trabalhadora, lócus da geração de demandas e disputas em torno do espaço construído e a construir, campo simbólico e espaço de lutas contra-hegemônicas, por parte dos estratos sociais desprivilegiados, que reivindicam acesso aos meios de consumo coletivo e inserção mais qualificada no mercado de trabalho.

Ao mesmo tempo que centraliza o dinamismo socioeconômico e a força expansiva da riqueza material, o espaço metropolitano concretiza a segmentação social, congrega aqueles que não foram absorvidos pelos mercados formais de trabalho e moradia, configurando variadas manifestações de periferização, marginalização, segregação socioespacial, diversas expressões de vulnerabilidade, etc. Na multidão da metrópole, apenas uma minoria detém o direito à cidade. Dessa forma, são produzidos permanentemente subterritórios com elevado grau de pobreza e exclusão social, consolidando verdadeiro apartheid social, com a multiplicação de diversos guetos e a potencialização de forças de fragmentação socioespacial e de divisão política.

Nesse espaço espraiado, difuso e conurbado, pode-se falar nas especificidades de uma teia econômica metropolitana que se arma, definindo, pelo porte e densidade das interações 
e articulações intra e intersetoriais, a construção de um tecido metropolitano territorializado com alguma coerência estruturada, que se produz e reproduz cotidianamente, conformando certo "sistema econômico" com algumas particularidades. Para além de um peculiar arranjo regional da estrutura de produção, com enorme diversidade de elos (com algum grau de complementaridade e integração) de cadeias produtivas (e de valor), de distribuição, consumo e troca implantadas em seu território, a metrópole é, ao mesmo tempo, geralmente o campo da diversificação produtiva, da diferenciação social e do trabalho variegado combinado.

Possui núcleo central com alta concentração de atividades administrativas, tráfego intenso, congestionamentos, deseconomias de aglomeração, fatores centrífugos que induzem à descentralização e ao surgimento de novos pontos e múltiplos subcentros de "gestão de atividades econômicas [...] novos focos descentralizados de transportes aparecem, identificando novos mercados metropolitanos de trabalho" (Corrêa, 1997, p. 173). Como já afirmamos, lembrando Jacobs (1969), no capitalismo, um trabalho puxa outro. Novas atividades atraem novos trabalhos que induzem à criação de outros nesses vários pontos espalhados no espaço urbano de porte, que se subdividem e formam outros. Variados arranjos urbano-regionais (Moura, 2009) vão se estruturando ao longo da rede urbana, formando arenas e bacias de emprego, pontos de aglomeração e de contatos pessoais que vão se estruturando desde de dentro do tecido difuso do espaço metropolitano.

Pode-se falar, também, em um mercado de trabalho especificamente metropolitano, de natureza peculiar, que se desenvolve e reproduz internamente no espaço de cada metrópole. Ou seja, há uma espécie de mercado "interno" de trabalho para determinada escala metropolitana. Analiticamente pode-se separar um mercado de trabalho "geral" e "externo" (às empresas e a circunscritos recortes territoriais) de um mercado de trabalho "interno" (que opera desde $o$ interior das grandes empresas e das grandes aglomerações territoriais). Essa internação das dinâmicas ocupacionais resulta da endogeneização, em determinado território metropolitano, de formas de recrutamento, condições específicas de funcionamento do mercado laboral, hierarquias salariais, segmentação, etc. Por exemplo, constrói-se determinado padrão com leques salariais que tomam a forma de um espectro de remunerações que guarda relação com as condições específicas da estrutura produtiva e do mercado de trabalho local e regional.

A economia metropolitana é determinada pela alta concentração de unidades econômicas, equipamentos urbanos de suporte, etc. que estruturam fluxos e lógicas específicas emanados de diversas frações do capital. Também cumpre papel de acelerar tais fluxos e agiliza o ritmo da acumulação de capital desse verdadeiro espaço da "unidade do diverso", que é o urbano metropolitano. Esses e outros são fatores de integração que dão coerência própria à dinâmica metropolitana, marcada por constante alargamento, sofisticação e aprofundamento da divisão social do trabalho em determinada porção territorial. Além disso, o espaço urbano, como ambiente construído para produção, intercâmbio e consumo, pode encurtar os ciclos do capital-dinheiro, do capital-produtivo e do capital-mercadoria, aumentando suas taxas de circulação e de rotação. 
A construção de modernas unidades produtivas, a expansão dos equipamentos de comércio (hipermercados, shopping centers, grandes revendedores de automóveis, etc.), empreendimentos de grande porte em alimentação, entretenimento e hotelaria, a ampliação da oferta de serviços profissionais (médicos, dentistas, advogados) e de serviços voltados para empresas (engenharia, consultorias, contabilidade, propaganda, marketing, serviços técnicos, etc.), vão consolidando também um padrão de consumo e um modo de vida tipicamente metropolitano. Isso também contribui para dinamizar a geração de emprego, renda e impostos, reforçando as expectativas favoráveis às máquinas de crescimento urbano-regionais e o papel de polo regional ou mesmo nacional do centro metropolitano.

Pode-se falar também de uma escala espacial metropolitana que vai se desenhando em nossos olhares e observações analíticas, narrativas e também na articulação de arenas de articulação de projetos políticos nesse nível espacial de apreensão dos fenômenos socioespaciais urbano-metropolitanos. A partir do olhar o sob prisma metropolitano, seria possível desvendar processos sociais, econômicos e territoriais singulares, pois a escala metropolitana parece ser um nível de transição, meso, de observação, intermediário entre as perspectivas locais, as microrregionais e as nacionais ou mundiais. Sua área de influência e alta capacidade de polarização submetem e enlaçam grande número de determinações que nesse plano escalar podem ser melhor analisadas.

Os enormes assentamentos humanos metropolitanos são sede e ambiente privilegiados da reprodução das classes e das atividades de produção, distribuição, troca e consumo. Atraem grandes massas populacionais, mas não têm, geralmente, capacidade, na medida suficiente, de geração de postos de trabalho e de absorção, nos circuitos modernos da economia, dessas pessoas. Assim, abrigam massas redundantes de população em relação às necessidades da acumulação de capital, organizando-os espacialmente em diversificados níveis de disponibilidades para sua exploração.

Nessa escala metropolitana, pode-se visualizar mais nitidamente os chamados problemas urbanos de natureza eminentemente metropolitanos. Espaços depositários e exponenciadores de toda a sorte de potencialidades, mas também de problemas, como pobreza, congestionamentos, poluições ambiental, sonora e visual, carências de transporte, habitação e emprego, segregação socioespacial, marginalidade social, desfiliação e avanço da cidade ilegal, além do sentimento de caos e ingovernabilidade de sua gestão, dados o nítido extravasamento e as intersecções das problemáticas municipais que compõem cada área metropolitana. 0 porte e a complexidade das carências conurbanas, geralmente exigentes de enorme montante de recursos e de arranjos institucionais e alianças políticas que ultrapassam os limites do desejável e do possível. Geralmente os problemas metropolitanos são de difícil decisão técnica, passíveis de enfrentamento através de variadas opções institucionais e de formatos de gestão. Isto é, a interdependência e a complementaridade entre seus diversos problemas comuns tornam muito complexa a tomada de decisão.

Na escala metropolitana, por sua natureza de espaços urbanos em suas formas mais avançadas, dotados de amplas complexidade 
e densidade, cumprem papel decisivo no funcionamento específico e na organização do mercado de trabalho assalariado. Isso pode ser observado pelo prisma da concentração de força de trabalho em determinado espaço, em quantidade e qualidade, para os diversos tipos de capitalistas, permitindo a possível superação de problemas de rigidez e estabilidade da oferta de trabalho e substituição de trabaIhadores numa base "diária". Sob o prisma de uma divisão social do trabalho mais sofisticada nas áreas metropolitanas, seria possível observar interações entre a maior densidade da população urbana, a concentração de fundos e de mercados de consumo de bens-salário, a elevada heterogeneidade das atividades econômicas e dos mercados de trabalho e a presença mais acentuada dos estratos médios-altos nas estruturas de classes sociais ligadas às funções de comando (Siqueira, 2010).

$\mathrm{Na}$ escala metropolitana se percebe de forma mais nítida, do que em qualquer outra escala espacial, o papel da mobilidade do trabalho, naquele sentido que lhe emprestou Gaudemar (1976), seu uso extensivo ou intensivo, a circulação das mais-valias absolutas ou relativas e a reprodução simples ou ampliada da força de trabalho, em uma visão de conjunto dos deslocamentos geográficos, setoriais e de ramos, profissionais, etc. Segundo ele, a mobilidade no capitalismo é um meio de adaptação da mão deobra. Nesse modo de produção, as deslocações de trabalho são forçadas e baseadas na domesticação, disciplinação, disponibilidade e docilidade dos seus corpos. Em contraponto a esses processos, Gaudemar propõe que os trabalhadores se organizem para levar à frente estratégias de contramobilidade ou de outra mobilidade.

Essa concepção lembra o que Harvey (2000) chamou de espaços da esperança, observando que os corpos (vivos) estão imersos em um processo social e não deveriam ser vistos como dóceis e passivos, mas como capacidade portadora de potencial transformador e criador de ação e vontade² que, por exemplo, pode empreender lutas por um salário vital. No sistema capitalista, a imposição de autoridade, controle e regulação tende a mover os planos individuais, privados e corporais, utilizando-os como correias de transmissão para seus desígnios. 0 capital circula através do corpo do(a) trabalhador(a) como capital variável, transformando-o em mero apêndice da própria circulação. A socialização do trabalhador nas condições de produção capitalista envolve o controle social bem amplo das capacidades vividas físicas e mentais. Os corpos, de modo geral, são utilizados como estratégia de acumulação, não obstante serem inseridos como corpos específicos, marcados em termos, por exemplo, raciais ou de gênero.

A escala metropolitana permite e potencializa a combinação do trabalho sob o comando despótico dos capitais, mas também a possibilidade para a organização das lutas contra-hegemônicas, podendo criar resistências, alteridades, insurgências, etc., que podem acumular forças políticas para superar o fragmento, engendrar coerências alternativas e novas subjetividades, construindo ressignificações, nesse espaço urbanizado complexo. 


\section{0 "Novo Brasil": mudanças socioeconômicas e desafios nos mundos da vida "dos de baixo" e do trabalho}

Embora o Brasil tenha construído virtuosamente a articulação econômica, a integração dos mercados regionais e a unidade nacional, todo o processo se deu sob um pacto de dominação ultraconservador, antidemocrático e antipopular. Apesar de ter engendrado socioeconomias urbano-regionais e rurais bastante complexas e modernas, estas estiveram, e continuam estando, submetidas à estrutura política arcaica desse pacto, que soldou alianças políticas e um contrato social produtor de todas (e simultâneas) expressões de desigualdades. Acredito que o país montou talvez a maior máquina de (re)produção de desigualdades do planeta. A expansão e a apropriação territoriais privatistas conformaram forças produtivas, mas também forças predativas, muito potentes, marcadas pela "fuga para a frente", com o privilégio da órbita da circulação dos capitais e o controle inabalável da propriedade (rural e urbana) fundiária que sempre costuraram as equações políticas e econômicas que produzem o espaço brasileiro. Na verdade, são forças totalitárias que, em sua extensividade e intensividade, dominam os espaços rurais, regionais e urbanos.

Para a melhor compreensão de tais processos, coloca-se a necessidade de verificar sucintamente os movimentos migratórios e demográficos no período recente, em grande parte motivados pelas novas dinâmicas econômicas territoriais.
A direção dos fluxos migratórios inter-regionais, bem como a intensidade com que ocorreram, precisa ser devidamente apropriada e consolidada pelas interpretações acerca das transformações territoriais na última década. A primeira década do século XXI revelou o reforço de dinâmicas espaciais paradoxais (concentração/desconcentração/seletividade), fluxos migratórios com perfil mais diversificado, requalificações territoriais e rearranjos das redes urbanas de menor hierarquia (IBGE, 2013). Embora construindo uma trajetória de urbanização mais polinucleada, com o avanço de centros regionais de maior expressão, as marcas estruturais dos grandes movimentos populacionais do século XX ainda afirmam a persistência de inércias colocadas pelos grandes estoques demográficos concentrados espacialmente, que reatualizam volumes de imigrantes e emigrantes ainda significativos nos grandes centros.

De qualquer forma, trata-se de uma dinâmica demográfica muito mais complexa e pluridirecional, pois

deixam de existir os estados ou regiões que se destacam somente por ser origem ou destino dos grandes fluxos migratórios. E esses contrafluxos são alimentados pelo aumento na reemigração interestadual de retorno, um dos fenômenos marcantes nas mudanças ocorridas no padrão migratório. (Brito, 2015, p. 21)

Não obstante, a persistência das grandes trajetórias migratórias anteriores ${ }^{3}$ impediu mudanças abruptas em relação ao antigo padrão, determinando que ocorra no presente maior combinação de variados padrões migratórios, revelando elementos de estabilização e regularidade dos caminhos estruturais migratórios já 
trilhados. Pelas sendas já percorridas "circulam fluxos e contrafluxos alimentados pelas migrações de retorno de curto prazo. Como um fenômeno tipicamente estrutural, a migração interna interage com as dinâmicas da economia e da sociedade, espelhando, espacialmente, as suas desigualdades regionais e sociais" (ibid., p. 25). Por exemplo, os espaços das três principais regiões metropolitanas, sobretudo São Paulo, Rio de Janeiro e Brasília, continuam a traçar as linhas principais das trajetórias migratórias brasileiras.

Entretanto deve-se destacar o crescimento dos municípios intermediários, posto que a taxa de crescimento da população total, entre 2000 e 2010, foi de 0,45\% para os municípios pequenos, 2,81\% para os médios, e 1,29\% para os grandes.

0 processo demográfico no Brasil ainda é muito dinâmico e ativo. Há mesmo uma arraigada "cultura migratória" (ibid., 2015), em que os deslocamentos espaciais com forte expectativa de ascensão social ainda persistem, mesmo quando a possibilidade de conjugar mobilidade espacial e mobilidade social, típica da trajetória histórica da mobilidade estrutural do século XX no Brasil (muito marcante até meados dos anos 1980), já não existe mais.

0 dinamismo da transformação material acelerada dos variados territórios brasileiros é marcante, e seus respectivos mercados de trabalho que vão sendo estruturados precisam ser analisados em pesquisas coletivas e abrangentes.

Recentemente, procuramos construir um esquema de análise e esboçar alguns fatos estilizados que pudessem provocar um debate que buscasse apreender e sistematizar, em traços largos, as recentes e mais gerais transformações territoriais brasileiras, pelas vias dos gastos públicos e dos investimentos públicos e privados em territórios distintos. Esquematizamos analiticamente 5 tipos-ideais de territórios, definidos pela natureza dos investimentos realizados e por seus específicos rebatimentos espaciais, que serão tratados em outro artigo, e que são importantes para pensar as perspectivas da produção social do espaço brasileiro. Delineamos, assim, 5 tipos de investimento e seus respectivos tipos de territórios impactados.

0 cenário mais provável, após o golpe midiático-jurídico-parlamentar, é o de desmontagem deste último tipo de investimento ou gasto público e de desmantelamento de direitos sociais instituídos na Constituição de 1988.

Não cabe aqui desenvolver uma caracterização mais aprofundada desses territórios, mas apenas deixar apontadas, para futuras pesquisas, quais seriam suas dinâmicas, inclusive nas mais prováveis metamorfoses em seus respectivos "mundos do trabalho".

Com o cenário atual de descomunal desmantelamento das regulações sociopolíticas do mercado autorregulado, as trajetórias mais prováveis e naturais decorrentes dos processos de despossessão e mercantilização, em cada um dos quatro primeiros territórios, seriam de enorme reconcentração na porção de maior desenvolvimento das forças produtivas, expansão interiorizada apenas de alguns enclaves de exportação, o aprofundamento na especialização regressiva em commodities e sua correspondente e customizada/dedicada infraestrutura logística e energética.

Sobre o último tipo de território, aquele das melhorias nas condições de vida proporcionadas pela ação pública, não se sabe se aquele conjunto abrangente de políticas sociais ${ }^{4}$ 


\begin{tabular}{|l|l|l|}
\hline \multicolumn{1}{|c|}{ Territórios } & \multicolumn{1}{|c|}{$\begin{array}{c}\text { Tipo-ideal dos investimentos em } \\
\text { territórios predominantemente } \\
\text { impactados e (re)definidos por: }\end{array}$} & Fatos estilizados \\
\hline Territórios Tipo I & $\begin{array}{l}\text { Forças inerciais dos fatores } \\
\text { de aglomeração e de urbanização }\end{array}$ & $\begin{array}{l}\text { Concentração no litoral, RMs, capitais e } \\
\text { cidades médias das vantagens locacionais } \\
\text { produtivas sobretudo na rede urbana do } \\
\text { sul-sudeste-litoral }\end{array}$ \\
\hline Territórios Tipo II & $\begin{array}{l}\text { Investimentos pontuais, tópicos } \\
\text { e enclavados }\end{array}$ & $\begin{array}{l}\text { Tendência a se constituírem em polos } \\
\text { isolados ou enclaves com baixa indução } \\
\text { do entorno e da hinterlândia }\end{array}$ \\
\hline Territórios Tipo III & $\begin{array}{l}\text { Demanda e preços mundiais } \\
\text { das commodities }\end{array}$ & $\begin{array}{l}\text { Vulnerabilidade marcantes em sua } \\
\text { dinâmica de crescimento }\end{array}$ \\
\hline Territórios Tipo IV & $\begin{array}{l}\text { Provisão de infraestrutura de transportes } \\
\text { e energia }\end{array}$ & $\begin{array}{l}\text { Constituição de eixos de expansão } \\
\text { e escoamento }\end{array}$ \\
\hline Territórios Tipo V & Impulsos das políticas sociais & $\begin{array}{l}\text { Chão da reprodução social cotidiana, } \\
\text { com melhoria das condições de vida }\end{array}$ \\
\hline
\end{tabular}

persistirá e em que intensidade. 0 certo é que tais políticas de proteção social, no passado recente, articularam-se nas regiões mais carentes e nas porções das áreas metropolitanas mais periféricas, com as melhorias do salário mínimo, da assistência social e previdenciária, do crédito consignado, dentre outras políticas públicas, realizando uma transformação impactante, sobretudo na base da pirâmide social brasileira.

No período entre 2003 e 2015 começou a ser constituída uma plataforma social ou terreno de maior homogeneidade social, um patamar básico de cidadania, um colchão amortecedor e um chão de segurança social e de acesso a direitos individuais, que garantiam condições mais dignas de vida, com a satisfação das necessidades essenciais e a possiblidade de ingresso e integração na sociedade moderna por parte das massas historicamente destituídas dos frutos do progresso no Brasil. A conjugação da valorização do salário mínimo, da maior formalização do mercado de trabalho, dos impactos dos Benefícios de Prestação Continuada (BPC) para deficientes e idosos, das melhorias na previdência e assistência sociais rural e urbana, os programas sociais, como por exemplo, Luz para Todos, Cisternas, Pronaf e MCMV, transformaram a vida cotidiana de algumas dezenas de milhões de pessoas. 0 mercado de trabalho reestruturou-se e ampliou sua formalização, embora em termos qualitativos tenha deixado a desejar, gerando, em sua maioria, postos de baixa remuneração em serviços domésticos, construção civil, segurança privada, dentre outros. 
0 crescimento mais inclusivo que se experimentou impactou diretamente aqueles setores fortemente condicionados pela elasticidade da demanda e pela oferta de crédito ao consumidor, pois são muito sensíveis às flutuações e dependentes das mudanças quantitativas e qualitativas nos mercados urbanos de trabalho e de consumo e da expansão da rendas nos meios rural e urbano.

Nos subramos do departamento de produção desses bens-salário que têm as características de mercadorias de consumo não durável, tais como aquelas tradicionais, como calçados de couro, vestuário e têxteis não padronizados, móveis mais simples, agroindústria de alimentos de baixa elaboração e bebidas, exibiram grande expansão e alguma pequena trajetória de deslocalização na direção das regiões periféricas, sobretudo em sua porção litorânea e dos grandes e médios centros urbanos.

Tal processo de transformação, dados os níveis aviltantes de pobreza e marginalidade entre as massas humanas mais destituídas de bens e direitos, representou verdadeira revolução, como, por exemplo, no semiárido nordestino e nas favelas das grandes metrópoles.

Aumentou o consumo, tanto de bens duráveis, quando de bens de não duráveis, com destaque para móveis, material eletrônico e de comunicação, eletrodomésticos, etc., além de gastos com passagens aéreas e planos privados de saúde, promovendo um ciclo expansivo, sobretudo no período do segundo governo Lula.

A expectativa era de que se engendrasse permanentemente um ciclo virtuoso entre consumo, investimento e produção local, que seria ampliado e regionalizado, sendo capaz de, pelo menos no médio e longo prazos, transformar, aprofundar e enraizar as estruturas produtivas e socioeconômicas das regiões menos desenvolvidas. Entretanto, grande parte dos efeitos multiplicadores e aceleradores de expansão e massificação do consumo dos mercados domésticos, que poderiam ter transformado mais profundamente as estruturas regionais mais débeis, acabou por ensejar a expansão da participação dos componentes importados, promovendo vazamento de renda.

Em suma, durante um determinado período, com destaque para o decênio de 2004/2014, o País logrou, em alguma medida, articular crescimento econômico e inclusão social, fazendo dialogar a política social com a ampliação do mercado interno de consumo de massa e a formalização das relações de trabalho. 0 resultado foi o aperfeiçoamento, a expansão e a consolidação, bem ou mal, de uma espécie de "sistema federativo de bem-estar social" (Monteiro Neto, 2015), que vinha sendo erguido desde a Constituição de 1988. Do ponto de vista das políticas urbanas e regionais, as problemáticas socioespaciais passaram a ser tratadas mais

a partir de seus atributos sociais, o foco da agenda social brasileira mais ampla. Mudou-se a orientação de políticas essenciais para a construção de uma nova trajetória de bem-estar nas regiões: do seu foco exclusivamente territorial para 0 do atendimento pessoal, direto, aos cidadãos, isto é, de políticas do tipo centrado em territórios particulares, place-based approach, para o tipo voltado para a meIhoria do bem-estar individual em geral, place-neutral approach. (Ibid., p. 22)

Não obstante, o que ficou patente no período entre 2003 e 2015 foram os colossais constrangimentos do padrão de alta 
concentração de renda e baixo acesso a riqueza e propriedade (sobretudo da terra, rural ou urbana) que restringem sobremaneira os mercados regionais de consumo e produção e criam barreiras enormes ao avanço de um tecido produtivo e empresarial mais endógeno, sobretudo nas regiões menos desenvolvidas, e a estruturação de mercados de trabalho mais robustos e de melhor qualidade.

Mesmo para os bens-salário, como alimentos, bebidas, confecções e calçados, os mercados regionais muitas vezes não tiveram economia de escopo ou de escala para competir com os produtos ofertados por empresas extrarregionais, no caso, sobretudo os vindo do Sul-Sudeste. Apesar do porte e da complexidade dos maiores polos regionais periféricos, revelou-se que a estreiteza dos mercados mais interiorizados ainda tem precedência diante dos impulsos que foram dinamizados pelo ativismo fiscal do Estado.

Naquele período, alargaram-se um pouco esses mercados urbano-regionais, engendrando potenciais futuras frentes de acumulação e mercados mais regionalizados para bens de baixa elaboração. Porém, ficou demonstrado que outros suportes transformadores, além do aporte de recursos e de infraestrutura, precisam melhorar e ter continuidade para se forjarem bases econômicas com maior autonomia e que se possam estruturar mercados de trabalho de melhor qualidade e com atividades e divisão social do trabalho mais aprofundadas e enraizadas e fatores de transformação estrutural mais potentes, sobretudo nos territórios de maior destituição.

Bercovici $(2015$, p. 81) sintetiza primorosamente nossos constrangimentos mais estruturais:
A garantia de ampliação de direitos sociais está estreitamente vinculada à universalização das políticas sociais, com igualdade de acesso e qualidade na prestações para todos, e ao desenvolvimento endógeno do país, com o mercado interno como centro dinâmico da economia e a internalização dos centros de decisão econômica, fundamentos essenciais, previstos constitucionalmente (artigos $3^{\circ}$, $6^{\circ}, 170$ e 219) para a implantação efetiva de uma sociedade industrial avançada e democrática entre nós. No entanto resta um obstáculo até hoje não ultrapassado: a distribuição da renda passa, necessariamente, pela questão da distribuição do patrimônio, ou seja, da propriedade privada. Esse é o núcleo essencial das reformas urbana e agrária nunca implementadas no Brasil.

A redemocratização e a Constituição Cidadã ajudaram a promover e a legitimar, minimamente, políticas sociais abrangentes, sobretudo sanitárias e educacionais, que ergueram certo patamar mínimo de condições materiais e cidadãs que vinham erguendo as bases de uma sociedade moderna de massas de alta complexidade de urbanização generalizada, total (Brenner, 2014), congregando a maior parte da população em uma sociedade urbana, embora persistam ruralidades muito marcantes em todo o heterogêneo território nacional.

Assim, no período entre 2003 e 2015 ocorreu intensa reconfiguração nas divisões inter-regionais e interurbanas do trabalho no Brasil, em razão da nossa avançada agenda de política social e dos grandes projetos de infraestrutura. As desigualdades interpessoais arrefeceram um pouco, mas as iniquidades inter-regionais e interurbanas brasileiras persistiram 
e ganharam outra natureza. As grandes questões macroestruturais civilizatórias não foram sequer tocadas no seio do Estado, não foram apropriadas pela maior parte da população, nem legitimado politicamente seu enfrentamento, o que requereria uma envergadura e uma complexidade da tarefa de resolução das problemáticas estruturais, que a correlação de forças políticas mais progressistas não lograram angariar. 0 resultado foi o agravamento do conflito de classes e a atual resolução autoritária, antipopular e conservadora, típica da história brasileira.

Na nova rodada de neoliberalização prefigurada pelo mercado, busca-se assegurar a violação e interdição de direitos da classe trabalhadora, com a aprovação da terceirização, não apenas das atividades-meio, como até agora, mas também a terceirização das atividades-fim.

\section{Considerações finais}

Nos últimos 20 anos, de 1995 a 2015, o Brasil sofreu três rodadas de neoliberalização. Apesar da potência das políticas sociais implementadas, em razão da política macroeconômica conservadora, uma reforma da previdência draconiana em 2003, as alianças com algumas das forças mais retrógradas e conservadoras do Brasil, a proteção ao rentismo e ao patrimonialismo e o não enfrentamento das questões fundiárias rurais e urbanas, pode-se denominar o período dos governos Lula e Dilma como uma espécie de onda intermediária no conjunto das três rodadas de neoliberalização que experimentamos desde o processo de abertura política pós-golpe de 1964. Assim, tivemos os governos FHC (1995/2002); o Lulismo (2003/2015) e o regime de mercado autorregulado Temer (2016...), que lançam mão de dispositivos, mecanismos e instrumentos bastante diferenciados de experimentações re-regulatórias, com variadas repercussões, nas três mercadorias fictícias: terra, dinheiro e trabalho.

Durante os conservadores anos 1990, marcados pelo Consenso de Washington, tivemos dois governos FHC (1995/2002), em que foram realizadas típicas estratégias de Roll-Back, de ataque ofensivo e desmantelamento de instituições públicas que regulavam o mercado, liberando suas forças para agir mais livremente. Foi um momento de privatizações, internacionalização da economia, destruição de postos de trabalho, de direitos e de garantia, com vigorosa repressão aos movimentos sociais.

Durante os governos Lula e Dilma, reestruturações regulatórias de grande alcance foram implementadas em uma rodada de Roll-Out, de re-regulação, reentrincheiramento, enfrentando modos de governança anteriores e criando refúgios de defesa que mesclaram conformação aos mercados com defesa de alguns direitos sociais.

Após o impeachment de Dilma, os processos neoliberalizantes se estendem e se arraigam, em mais uma rodada de liberar o "moinho satânico" (Polanyi, 1980) do mercado para funcionar sem peias, em um momento de re-des-construção institucional e ataque à democracia.

0 que é impressionante é que como, em cerca de 20 anos, o Brasil, demonstrando a fragilidade de sua jovem experiência 
democrática, construiu três rodadas de neoliberalização bastante distintas, um Roll-Back, um Roll-Out e um novo Roll-Back ainda mais radical que o primeiro.

Com nuances que poderiam se distinguidas entre as três rodadas de neoliberalização dos últimos dois decênios, em todas elas persistiu a redistribuição em favor das rendas do capital, em detrimento das rendas do trabalho. Mesmo na rodada Roll-Out do Lulismo, que promoveu importante distribuição pessoal da renda, com aumento da homogeneidade social, a chamada distribuição funcional da renda não mudou muito a favor da massa de salários em relação à massa de lucros.

Os reinos da finança, do agronegócio e da internacionalização aberta ganham terreno. Por outro lado o aprofundamento da crise, a violência multidimensional, os graves problemas urbanos, demonstram a fragilidade do mercado de trabalho brasileiro, que cria novos postos em cada ciclo espasmódico e depois os destrói rapidamente. Além disso, o endividamento familiar dos mais pobres é crescente, em um momento de aumento do desemprego, recessão e retirada de seu direitos duramente conquistados.

A conjuntura atual é de exacerbação do novo conflito urbano-metropolitano, com a complexidade das disputas das variadas subfrações de classe, com enorme fragmentação e despolitização, convivendo com novas dinâmicas dos movimentos sociais por justiça socioespacial.

Historicamente, mesmo com a modernização urbanizada, não se consolidam legitimação e força política suficientes para romper 0 impasse da implementação de políticas sociais e habilitação pela educação e pela propriedade em grande escala.

As transformações sociais dos últimos treze anos incorporaram aos mercados capitalistas (de consumo, de trabalho, de moradia, etc.) milhões de brasileiros que antes faziam parte da histórica massa redundante e marginalizada do nosso processo de urbanização subdesenvolvida. As perguntas extremamente difíceis de serem respondidas, que requerem ainda inúmeras e intensas pesquisas coletivas são, dentre outras que poderiam ser formuladas: "0 que esperar dessa nova dinâmica do conflito de classes nos espaços urbanos brasileiros?"; "Até onde os ultraconservadores, agora no poder, lograrão implementar seu projeto de retrocesso social e político?"; "Qual a trajetória futura material, simbólica, cultural e política dos "novos incluídos?"; "Há possibilidade de construir, no futuro, alianças deles com as forças mais progressistas?"; ou, "Se eles deixarem de ser 'incluídos', e se tornarem 're-excluídos', como reagirão?".

\section{Carlos Antônio Brandão}

Universidade Federal do Rio de Janeiro, Instituto de Pesquisa e Planejamento Urbano e Regional. Rio de Janeiro, RJ/Brasil brandaoufrj@gmail.com 


\section{Notas}

(*) Agradeço os comentários dos pareceristas anônimos cujas sugestões foram fundamentais para o aprimoramento do artigo.

(1) Mobilizar e concentrar excedente social em base permanente implica a criação de uma economia espacial permanente e a perpetuação de algumas condições (densidade populacional, comunicação e acesso, etc.) (Harvey, 1973, p. 205).

(2) 'Não é casual o fato de Marx adicionar o qualificativo 'vivo' ao trabalho incorporado à circulação do capital variável, não apenas para acentuar suas qualidades fundamentais de dinamismo e criatividade, mas também para indicar onde está a força de vida e do poder subversivo para a mudança" (Harvey, 2000, p. 162).

(3) "Do ponto de vista migratório, é a integração hierárquica dos diferentes espaços de influência migratória, expressa na inércia das trajetórias migratórias, que explica a redução gradativa dos índices de eficácia migratória. O processo de concentração, nas grandes cidades não metropolitanas e nas regiões metropolitanas, ainda persiste e continuará a persistir. Contudo, ele é mais bem compreendido quando considerado como um movimento que se dá no âmbito da hierarquização da rede urbana que articula municípios heterogêneos ou, em outras palavras, que articula espaços diferenciados de influência migratória” (Brito e Pinho, 2015, p. 25).

(4) “Os resultados (até outubro de 2014) falam por si: 22 milhões de brasileiras e brasileiros superaram a extrema pobreza com o Bolsa Família; 1,35 milhão de famílias que eram extremamente pobres foram incluídas no Cadastro Único pela Busca Ativa, e imediatamente entraram no Bolsa Família; mais de 1,5 milhão de pessoas de baixa renda se inscreveram em cursos de qualificação profissional do Pronatec Brasil sem Miséria; mais de 400 mil beneficiários do Bolsa Família se formalizaram como microempreendedores individuais; 3,6 milhões de pessoas do Bolsa Família fizeram operações de microcrédito produtivo orientado do Programa Crescer; 349 mil famílias de agricultores de baixíssima renda do semiárido receberam serviços de assistência técnica no semiárido, e 131 mil já estão recebendo recursos de Fomento para ajudar a estruturar sua produção; 750 mil cisternas de água para consumo foram entregues, também no semiárido; 69,8 mil famílias foram beneficiadas pelo Programa Bolsa Verde; 267 mil famílias do Bolsa Família receberam ligações de energia elétrica do Programa Luz para Todos; 702,8 mil crianças do Bolsa Família estão matriculadas em creches; 35,7 mil escolas com maioria de estudantes do Bolsa Família agora tem ensino em turno integral com o Programa Mais Educação; e 388 mil famílias do Bolsa Família foram beneficiadas pelo Minha Casa Minha Vida" Brasil/MDS (2014). 


\section{Referências}

BERCOVICI, G. (2015). "A questão social, a Constituição de 1988 e os desafios do desenvolvimento". In: SOUZA, P. (org.). Brasil, sociedade em movimento. São Paulo/Rio de janeiro, Paz e Terra/Centro Celso Furtado.

BRASIL/MDS (2014). O Brasil sem miséria. Brasília, Ministério do Desenvolvimento Social.

BRANDÃO, C.; FERNÁNDEZ, V. R. e RIBEIRO, L. C. Q. (2016). Escalas espaciais, reescalonamentos e estatalidades: lições e desafios para América Latina. Rio de Janeiro, Letra Capital (no prelo).

BRENNER, N. (2004). New state spaces: urban governance and the rescaling of statehood. Oxford, Oxford University Press.

(ed.) (2014). Implosions/explosions: towards a study of planetary urbanization. Berlim, Jovis.

BRENNER, N.; PECK, J. e THEODORE, N. (2012). Após a neoliberalização?. Cadernos Metrópole. São Paulo, v. 14, n. 27, pp. 15-39.

BRITO, F. e PINHO, B. A. (2015). Distribuição espacial da população, urbanização e migrações internas no Brasil. Texto para Discussão n. 524. Belo Horizonte, UFMG/Cedeplar.

BRITO, F. (2015). A transição para um novo padrão migratório no Brasil. Texto para Discussão n. 526. Belo Horizonte, UFMG/Cedeplar..

CASTEL, R. (1998). O fim do trabalho: um mito desmobilizador. CEPAT Informa n. 44. Brasília, Cepat. (2010). As metamorfoses da questão social: uma crônica do salário. Petrópolis, Vozes.

(2012). El ascenso de las incertidumbres: trabajo, protecciones, estatuto del individuo. Buenos Aires, Fondo de Cultura Económica.

CASTELLS, M. (1983). A questão urbana. Rio de Janeiro, Paz e Terra [1a ed. 1972].

CHESNAIS, F. (2005). A finança mundial: raízes sociais e políticas, configurações, consequências. São Paulo, Boitempo.

CINTRA, M. (2015). Turbulência global não tem prazo para acabar. Rumos do Desenvolvimento, Ano 12, Edição 87, pp. 54-58. Ipea.

CORRÊA, R. L. (1997). Trajetórias geográficas. Rio de Janeiro, Bertrand Brasil.

(2007). "Construindo o conceito de cidade média". In: SPOSITO, M. E. B. (org.). Cidades médias: espaços em transição. São Paulo, Expressão Popular.

DESAI, R. (2013). Geopolitical economy: after US hegemony, globalization and empire. Londres, Pluto Press.

FERNÁNDEZ, V. R. (2016a). Desde el laboratorio neo-desarrollista a la resurgencia neoliberal: uma revisión creativa del 'doble movimiento' polanyiano en América Latina. Revista Estado y Políticas Públicas, n. 7, pp. 21-47.

(2016b). La trilogía del erizo-zorro: redes globales, trayectorias nacionales y dinámicas regionales desde la periferia. Buenos Aires, Editorial Anthropos /Santa Fe y Ediciones de la Universidad Nacional del Litoral (no prelo). 
FIORI, J. L. (2014). História, estratégia e desenvolvimento: para uma geopolítica do capitalismo. São Paulo, Boitempo.

GAUDEMAR, J. (1976). Mobilidade do trabalho e acumulação de capital. Lisboa, Editorial Estampa. GORZ, A. (1999). O fim do trabalho assalariado. CEPAT Informa n. 49. Brasília, Cepat.

GRAMSCI, A. (2007). Cadernos do cárcere. Rio de Janeiro, Civilização Brasileira, 7 v. [1a ed. 1937].

HARVEY, D. (1980). A justiça social e a cidade. São Paulo, Hucitec [1a ed. 1973]. (2000). Espaços da esperança. São Paulo, Loyola. (2016). 17 contradições e o fim do capitalismo. São Paulo, Boitempo.

IBGE (2013). Atlas do Censo Demográfico de 2010. Rio de Janeiro, IBGE.

JACOBS, J. (1969). The economy of cities. Nova York, Vintage Books.

JESSOP, B. (2006). ¿Narrando el futuro de la economía nacional e el estado nacional? puntos a considerar acerca del replanteo de la regulação e la re-invenção de la gobernancia. Documentos y Aportes en Administração Pública y Gestão Estatal, año 6, n. 7, pp. 7-44.

KOWARICK, L. (1979). A espoliação urbana. Rio de Janeiro, Paz e Terra.

LOJKINE, J. [1997]. O marxismo, o Estado e a questão urbana. São Paulo, Martins Fontes [1a ed. 1979].

MARICATO, E. (2015). Para entender a crise urbana. São Paulo, Expressão Popular.

MEDEIROS, C. A. (2006). A China como um duplo polo na economia mundial e a recentralização asiática. Revista de Economia Política, v. 26, pp. 381-400.

MONTEIRO NETO, A. (2015). Políticas de desenvolvimento, território e pacto federativo: avanços e limitações no quadro atual (2000/2012). Revista Política e Planejamento Regional, v. 2, n. 1, pp. 19-38.

MOURA, R. (2009).Arranjosurbano-regionaisno Brasil:umaanálise comfocoem Curitiba. Tesede Doutorado. Curitiba, Universidade Federal do Paraná. Disponível em: http://www.observatoriodasmetropoles. net/images/abook_file/arranjos_urbanoregionais_analise_curitiba.pdf. Acesso em: 20 out 2010.

OFFE, C. (1985). “A economia política do mercado de trabalho”. In: OFFE, C. O capitalismo desorganizado: transformações contemporâneas do trabalho e da política. São Paulo, Brasiliense.

OHMAE, K. (1996). O fim do Estado-Nação: a ascensão das economias regionais. Rio de Janeiro, Campus.

OLIVEIRA, F. (1979). “Apresentação”. In: MARICATO, E. (org.). A produção capitalista da casa (e da cidade) no Brasil industrial. São Paulo, Alfa Ômega.

(2003). Crítica à razão dualista / Ornitorrinco. São Paulo, Boitempo.

PARK, R. E. (1991). “Cidade: sugestões para a investigação do comportamento humano no meio urbano" In: VELHO, O. (org.). O fenômeno urbano. Rio de Janeiro, Zahar.

PECK, J. (2010a). Constructions of neoliberal reason. Oxford, Oxford University Press.

(2010b). “Economías políticas de escala: políticas rápidas, relaciones interescalares y workfare neoliberal”. In: FERNANDEZ, V. R. e BRANDÃO, C. A. (directores). Escalas y políticas del desarrollo regional: desafíos para América Latina. Madri, Miño y Dávila, pp. 77-120. 
PECK, J. e THEODORE, N. (2010). Recombinant workfare, across the Americas: transnationalizing fast social policy. Geoforum, v. 41, n. 2, pp. 195-208.

POCHMANN, M. (2008). O emprego no desenvolvimento da nação. São Paulo, Boitempo.

POLANY, K. (1980). A grande transformação: as origens da nossa época. Rio de Janeiro, Campus [1944]. SPOSITO, M. E. B. (org.). (2007). Cidades médias: espaços em transição. São Paulo, Expressão Popular. SIQUEIRA, H. (2010). Economia metropolitana e mercado de trabalho. Rio de Janeiro, E-papers.

Texto recebido em 6/out/2016 Texto aprovado em 21/nov/2016 
